\title{
Ann M. Gilroy: Anatomy: An Essential Textbook, Latin Nomenclature
}

\author{
Thieme Verlag, New York, Stuttgart, Delhi, Rio de Janeiro, 2015, 532 pp, 701 ill., \\ Softcover, EUR (D) 49.99, EUR (A) 51,40, CHF 57,50, ISBN: 978-1-62623-117-7
}

\author{
Pr Pierre Kehr ${ }^{1}$
}

Received: 20 April 2016/Accepted: 25 April 2016/Published online: 13 May 2016

(C) Springer-Verlag France 2016

This handbook of anatomy is original because the authors chose the international Latin nomenclature, which constitutes a challenge in the Anglo-Saxon linguistic world. The illustrations are absolutely splendid.

The plan is traditional: rachis, thoraxes, abdomen, pelvises and périnée, upper limb, lower extremity, head and neck are followed. Each chapter ends in a series of questions with multiple choices, in general of five proposals which makes it possible to the reader to test his knowledge, then not making a fresh start of reading the answers and the explanations there related. These questions are intended as well to students as with experienced specialists. This interactivity is increased by a possible connection with the website of WinkingSkull.

Splendid book of human anatomy to advising not only with all the students but also to all the doctors and surgeons impassioned by this fundamental science.

Compliance with ethical standards

Conflict of interest None.

Pr Pierre Kehr

pierre.kehr@gmail.com

1 Strasbourg, France 